\title{
Conversation Analytic Studies of Psychoanalytic Dialogue: An Introduction to this Special Volume
}

\author{
Michael B. Buchholz ${ }^{1}$ \\ International Psychoanalytic University (IPU)
}

\section{Parallel Actions}

Two parallel strands developed since the start of the century in psychoanalysis. One was the relational turn initiated by Steven Mitchell (Mitchell, 1988, 1998) and his many inspiring and inspired co-workers (Aron, 2006; Hoffman, 1999, 2006; Knoblauch, 2007), just to mention a few of those authors whose enormous influence in demystifying some psychoanalytic myths held for irrefutable for so many years can be felt from their writings.

Just to mention one point. In "Influence and Autonomy" Mitchell (1997) described his study of psychoanalytic therapists' intervention in the process. He provided a detailed description of what went on in the patients' mind (as the analysts thought it was) and what the analysts then said was a summary of the kind, such as "these connections were interpreted to the patient". No clear representation of what the analysts said nor the answer the patients gave to the interpretation. The patient was viewed as deliverer of "material" and the analyst delivered "interpretations". As long as such a model of division of labor seemed to work we had something called "classical psychoanalysis". Doubts increased if what we think we do really is what is done. Meanwhile these doubts are certified:

"We believe that there has not been as much diligence in confronting the reality of our clinical practice, that is, what it really is, and not what we say it is or what we would like it to be" (Canestri, 2011, p. XX).

Parallel voices were heard from one of the most experienced scholars in infant research:

"Although the coconstruction of the intersubjective field is currently of great interest to psychoanalysts, detailed clinical material illustrating the nonverbal and implicit dimensions of this process remains rare" (Beebe, 2012, p. 97).

While many confessed to interpersonalist or intersubjective or relational terminology the empirical study of what was really done in details was still hardly studied by psychoanalysts (be them classical or relational!!). However, research was done by a group of conversation analytic researchers who turned away from studying court interaction or medical discourse in the consulting room of psychotherapists of various schools. The study of psychotherapeutic and psychoanalytic discourse was conducted by

1 Correspondence concerning this article should be addressed to Prof. Michael Buchholz, International Psychoanalytic University (IPU), Stromstr. 2-3. 10555 Berlin, Germany. E-mail: michael.buchholz@ipu-berlin.de.

Language and Psychoanalysis, 2016, 5 (2), 4-10

http://dx.doi.org/10.7565/landp.v5i2.1556 
many researchers with a linguistic or sociological training and interest (see Kächele's concluding remarks), however this was seldom recognized by psychoanalysts. Their publications got published in journals out of reach for many practitioners who practiced eight hours or more per day, although the findings would have interested them. Another obstacle might have been the terminology of linguistic and social scientific jargon, despite that many clinicians readily joined neuro-psychoanalytic research and learned how to read these publications and study its terminology.

\section{The Primacy of Interaction}

This situation changed when conversation analysis (CA) appeared on the stage. Although blackened as "behaviouristic" this turned out as an error. Gail Jefferson, editor of the "Lectures on Conversation" by Harvey Sacks (Sacks \& Jefferson, 1992, 1995) after his untimely death in 1975, wrote a lot of papers that took up psychoanalytic topics, such as Freudian slips (Jefferson, 1996). What she found was close to the original Freudian approach, however, Freud's observations could be confirmed and extended. One of Sacks' co-authors, Emanuel Schegloff, became one of the most prominent CAresearchers and he wrote a paper "The surfacing of the suppressed" the title of which took up the Freudian "sound". What he discovered was the following: When a slip happened in a conversation and its topic goes unnoticed, even though, it is relevant for the interactants, there is a strong tendency for another slip to happen in the next one or two minutes of the conversation. He gathered a lot of material with such observations. Schegloff (2000) published his study in German and two psychoanalysts (Kazanskaya \& Kächele, 2000) wrote a comment which substantiated the convergence of CA and the original Freudian position.

In 2008 it was time for a compilation of CA-results in psychotherapy process research (Peräkylä, Antaki, Vehviläinen, \& Leudar, 2008). A lot of studies turned to the dimension of therapeutic empathy (Weiste, Peräkylä, \& Perakyla, 2014) and it seemed that empathy is a subject that could be studied by CA. Earlier attempts had warned how complex the study of empathy is (Elliott et al., 1982), because achieving high agreements among raters cannot be expected.

With such developments, CA in psychotherapy loosened a little the singular fixation to linguistics only, and increasingly turned to the social dimension of human interaction. CA was the offspring of linguistics and social science. A more social orientation originated from the work of Goffman (Goffman, 1981). He invested much energy to embed interaction and conversation in relevant institutional contexts (Goffman, 1974, 1986). What happened in psychotherapeutic treatment rooms, thus, could be understood as a special type of institutional interaction - dealing with emotions. This was another challenge for CA. The gathered papers (Peräkylä \& Sorjonen, 2012) give sustained impression of CA-power to deal with emotions as very influential "things" - in interaction, not in individuals alone. CA kept the interactive primacy. Interactive - as opposed to an individualistic - primacy had been debated in a clinically important text (Peräkylä, 2015); Goffman's “face-work" and Freud's term of "narcissism" were brought into a fruitful dialogue.

\section{New Methodological Problems}

However, interactive primacy poses a lot of new methodological problems. Schegloff had turned to the macro-micro-problem in early years (Schegloff, 1987). He refused to Language and Psychoanalysis, 2016, 5 (2), 4-10 
explain what happens in conversational interaction by abstract concepts which pre-exist in the interpreter's mind so readily. This was supported by a German social psychologist (Graumann, 1979) who wondered about psychologists' shyness towards interaction. Schegloff showed the relevance of details overlooked regularly, when using abstract and prefabricated concepts too fast.

Let me give just one example of the relevance of details. In our CEMPP-project (CEMPP $=$ Conversation Analysis of Empathy in Psychotherapy Process) we compare psychoanalytic, cognitive behavioural and psychodynamic psychotherapy. Of each therapeutic school we have five patient-therapist dyads using one session form the start, the middle-phase of therapy and of the terminal phase. Therefore, for each psychotherapeutic dyad three sessions are available (beginning, middle, end), and in total we have 15 sessions available per therapy school.

While transcribing this material, we observed that so-called "change-of-state-tokens" (Heritage, 1984) were uttered in some sessions more often than in others. In change-ofstate tokens, "hms" are displayed in a special prosodic fashion: they have two summits and a special shape of intonation. Together with a relatively strong increase of pitch and a slow decrease they have the potential to inform the speaker that the listener's "state" has changed; he understands a story better when, e.g., a missing detail is told or when the change of perspective in the narration is understood as an important detail. This is undoubtedly important when you think of a therapeutic intake interview while listening to a patient's narrative, complaints or biography and when you utter such a token the patient experiences a) that you are an active listener and b) that the patient has the influence to change your state-of-mind.

Patients value when they can influence their therapist. It increases their feeling of agency and self-worth. Undoubtedly, this is an important interactional feature. However, we do not know of any study in psychotherapy process research having mentioned this feature before. Narrative Process Coding Systems (Angus et al., 2012; Boritz, Bryntwick, Angus, Greenberg, \& Constantino, 2014; Singer \& Bonalume, 2010) do not code therapist's utterances while the patients narrative activities, they are oriented to the patient in order to measure improvement (Mendes et al., 2010). Nonetheless, from a CA-point of view this methodology ignores the therapist's contribution in narrative co-constructing.

Florian Dreyer (this volume) presents an interesting example of how influential the therapist"s "change-of-state"-tokens are - above all, if they are missed. Adding to his findings we worked on coding all change-of-state-tokens in our transcripts and found the following distribution (see Figure 1): 


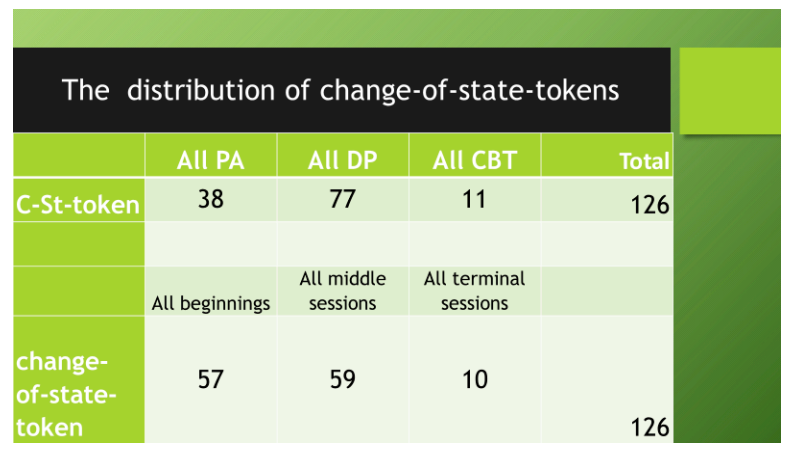

Figure 1

Change-of-state-token distribution

Over all sessions, from beginning to the end, CBT therapist utter a very small number of change-of-state-tokens (CST), less than one per session. The psychodynamic therapists use it most often. Is this a result attributable to therapists' orientation alone? The answer is no, as there is obviously a time factor. If you sum up across all therapies and list according to the state of "relational development", you can find another result: In the beginning CSTs are as often as in the middle; at the end of therapies this sign of acquiring a new understanding in interaction decreases.

This is a very simple result. Nevertheless, it confronts us with some methodological questions. First, does this difference represent a difference of approach between psychoanalysis, psychodynamic psychotherapy and cognitive-behavioural therapy? Or is it more of the therapist's personality? In what relation stands such a result of microanalysis to meso- or macro-levels of outcome? How can the relationship of micro-details and macro-outcome be thought? One way is to think of micro-events like the brick stones while building a house. Putting one above the other you can observe how the walls of your house grow.

What about the role of the architect with a plan? All brick stones look the same. However, there is a difference. Some of them are cornerstones, others not. Removing the cornerstones or those below the others will produce different results. One important methodological lecture to learn from this way of thinking is that same things are not always the same. This must have consequences for a "coding and counting" - approach (Kondratyuk \& Peräkylä, 2011) which treats every element with the same code as if it was the same.

The other way is to think of the micro-macro-relationship in a more systemic fashion including temporality. The effect of omitting a CST in the first meetings might be greater than at the end, irrespective of how positive or negative this effect might be. There is something else to be mentioned. If it is right what CA-researchers attribute to CSTs then each CST could be considered according to a part-whole principle. Uttering a CST is, then, not only an element to be counted. For the individual dyad such an element might direct the interactive course slowly in different directions. If a CST is recognized favourably by a patient it might become part of a hopeful investment, considering the therapist to be a person who does not stubbornly following his own rules, but who is a 
person accessible to the influence of the patient. Taking this into account, a CA procedure does not simply count CSTs, but include the responses of patients to CSTs.

Viewing these two alternatives of the micro-macro-problem, both end with an unresolvable clash of the wish to keep to the individualized meanings in the dyad and the wish to understand larger groups of treatment. The task for the future is to find good answers to this, and other types of unresolved methodological problems. In this edition Marie-Luise Alder presents a cases of a very unusual dream telling, in which telling a dream is used as an allusion to the ongoing interaction. Michael Dittmann studies not the final phase of a therapy, but how single sessions are closed with interesting results, e.g., something he calls JETH (Joint evaluation of therapeutic help). Such evaluation is done not by external researchers but by the interactants themselves. The other attempt here is to compare good and less good solutions for typical problematic situations in therapies, which is my contribution. Laura Cariola explores patients' semantic changes in patient person-centred therapy and how it relates to the mind-body paradigm by focusing on body boundaries.

We hope that readers might become interested in this kind of study, combining CA and clinical competence in order to better understand what we mean when speaking of the therapeutic process. 


\section{References}

Angus, L. E., Lewin, J., Boritz, T. Z., Bryntwick, E., Carpenter, N., Watson-Gaze, J., \& Greenberg, L. S. (2012). Narrative process coding system: A dialectical constructivist approach to assessing client change processes in emotion-focused therapy of depression. Research in Psychotherapy: Psychopathology, Process and Outcome, 15, 54-61.

Aron, L. (2006). Analytic impasse and the third: Clinical implications of intersubjective theory. International Journal of Psychoanalysis, 87, 349-368.

Beebe, B. (2012). Faces in relation: A case study. In L. Aron \& A. Harris (Eds.), Relational psychoanalysis Vol. 5 - Evolution of process (pp. 97-142). New York, NY: Routledge.

Boritz, T. Z., Bryntwick, E., Angus, L., Greenberg, L. S., \& Constantino, M. J. (2014). Narrative and emotion process in psychotherapy: An empirical test of the Narrative-Emotion Process Coding System (NEPCS). Psychotherapy Research, 24, 594-607. doi:10.1080/10503307.2013.851426

Canestri, J. (Ed.). (2011). Putting theory to work. How are theories actually used in practice? London, UK: Karnac Books.

Elliott, R., Filipovich, H., Harrigan, L., Graynor, J., Reimschuessel, C., \& Zapadka, J. K. (1982). Measuring response empathy. The development of a multicomponent rating scale. Journal of Counseling Psychology, 29, 379-387.

Goffman, E. (1974/1986). Frame analysis: An essay on the organization of experience. Harper colophon books: CN 372. New York, NY: Harper \& Row.

Goffman, E. (1981). Forms of talk. University of Pennsylvania publications in conduct and communication. Philadelphia, PA: University of Pennsylvania Press.

Graumann, C. F. (1979). Die Scheu des Psychologen vor der Interaktion. Ein Schisma und seine Geschichte. Zeitschrift für Sozialpsychologie, 10, 284-304.

Heritage, J. (1984). A change-of-state token and aspects of its sequential placement. In J. M. Atkinson \& J. Heritage (Eds.), Structures of social action (pp. 299-346). New York, NY: Cambridge University Press.

Hoffman, I. Z. (1999). The patient as interpreter of the analyst's experience (1983). In S. A. Mitchell \& L. Aron (Eds.), Relational psychoanalysis. The emergence of a tradition (vol. I) (Vol. 14, pp. 39-76). London, UK: The Analytic Press.

Hoffman, I. Z. (2006). The myths of free association and the potentials of the analytic relationship. International Journal of Psychoanalysis, 87, 43-61.

Jefferson, G. (1996). On the poetics of ordinary ztalk. Text and Performance Quarterly, $16,1-61$.

Kazanskaya A, Kächele H. (2000) Kommentar zu E. Schegloff: Das Wiederauftauchen des Unterdrückten. Psychotherapie und Sozialwissenschaft, 2, 30-33

Knoblauch, S. H. (2007). The perversion of language in the analyst's activity: Navigating the rhythms of embodiment and symbolization. International Forum of Psychoanalysis, 16, 38-42.

Kondratyuk, N., \& Peräkylä, A. (2011). Therapeutic work with the present moment: A comparative conversation analysis of existential and cognitive therapies. Psychotherapy Research, 21, 316-330.

Mendes, I., Ribeiro, A. P., Angus, L. E., Greenberg, L. S., Sousa, I., \& Goncalves, M. M. (2010). Narrative change in emotion-focused therapy: How is change constructed through the lens of the innovative moments coding system? Psychotherapy Research, 20, 692-701. 
Mitchell, S. A. (1988). Relational concepts in psychoanalysis. An integration. Cambridge, MA: Harvard University Press.

Mitchell, S. A. (1997). Influence and autonomy in psychoanalysis. Hillsdale, NJ: The Analytic Press.

Mitchell, S. A. (1998). The analyst's knowledge and authority. Psychoanalytic Quarterly, LXVII, 1-31.

Peräkylä, A. (2015). From narcissism to face work: Two views on the self in Ssocial interaction. American Journal of Sociology, 121, 445-474.

Peräkylä, A., Antaki, C., Vehviläinen, S., \& Leudar, I. (Eds.). (2008). Conversation analysis and psychotherapy. Cambridge, UK: Cambridge University Press.

Peräkylä, A., \& Sorjonen, M.-L. (Eds.). (2012). Emotion in interaction. New York, NY: Oxford University Press.

Sacks, H., \& Jefferson, G. (1992 // 1995). Lectures on conversation. Edited by Gail Jefferson, with an introduction by Emanuel A. Schegloff. Oxford, UK: Basil Blackwell.

Schegloff, E. A. (1987). Between macro and micro: Contexts and other connections. In J. C. Alexander, B. Giesen, R. Münch, \& N. J. Smelser (Eds.), The micro-macro link (pp. 207-236). Berkeley, CA: University of California Press.

Schegloff, E. A. (2000). Das Wiederauftauchen des Unterdrückten. Psychotherapie und Sozialwissenschaft, 2, 3-29.

Schegloff, E. A. (2003). The Surfacing of the Suppressed. In P. J. Glenn, C. D. LeBaron, \& J. S. Mandelbaum (Eds.), Studies in language and social interaction. In honour of Robert Hopper (pp. 241-263). London, UK: Lawrence Erlbaum.

Singer, J., \& Bonalume, L. (2010). Autobiographical memory narratives in psychotherapy: A coding system applied to the case of Cynthia. Pragmatic Case Studies in Psychotherapy, 6, 134-188.

Weiste, E., \& Peräkylä, A. (2014). Prosody and empathic communication in psychotherapy interaction. Psychotherapy Research, 24, 687-701. 